\title{
Effectiveness of a multidimensional approach for prevention of ventilator-associated pneumonia in 11 adult intensive care units from 10 cities of Turkey: findings of the International Nosocomial Infection Control Consortium (INICC)
}

\author{
H. Leblebicioglu • A. N. Yalcin • V. D. Rosenthal $\cdot$ I. Koksal • F. Sirmatel · S. Unal $\cdot$ H. Turgut \\ D. Ozdemir · G. Ersoz $\cdot$ C. Uzun $\cdot$ S. Ulusoy $\cdot$ S. Esen $\cdot$ F. Ulger $\cdot$ A. Dilek $\cdot$ H. Yilmaz $\cdot$ O. Turhan \\ N. Gunay $\cdot$ E. Gumus $\cdot$ O. Dursun $\cdot$ G. Yýlmaz $\cdot$ S. Kaya $\cdot$ H. Ulusoy $\cdot$ M. Cengiz $\cdot$ L. Yilmaz $\cdot$ \\ G. Yildirim • A. Topeli · S. Sacar • H. Sungurtekin · D. Uğurcan · M. F. Geyik · A. Şahin • \\ S. Erdogan - A. Kaya $\cdot$ N. Kuyucu $\cdot$ B. Arda $\cdot$ F. Bacakoglu
}

Received: 23 July 2012/ Accepted: 9 January 2013 / Published online: 26 January 2013

(C) Springer-Verlag Berlin Heidelberg 2013

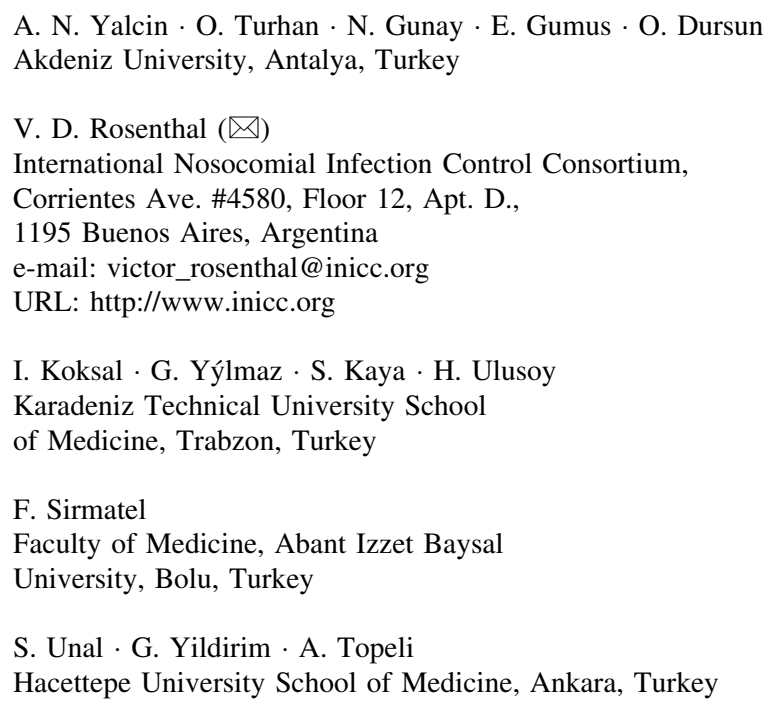

\begin{abstract}
Purpose To evaluate the impact of the International
Abstract
Purpose To evaluate the impact of the International Nosocomial Infection Control Consortium (INICC) multidimensional approach on the reduction of ventilator-associated pneumonia (VAP) in adult patients hospitalized in 11 intensive care units (ICUs), from 10 hospitals, members of the INICC, in 10 cities of Turkey.

Methods A prospective active before-after surveillance study was conducted to determine the effect of the INICC multidimensional approach in the VAP rate. The study was divided into two phases. In phase 1 , active prospective surveillance of VAP was conducted using the definitions of the Centers for Disease Control and Prevention National Health
\end{abstract}

H. Leblebicioglu $\cdot$ S. Esen · F. Ulger - A. Dilek · H. Yilmaz

Ondokuz Mayis University Medical School, Samsun, Turkey

Safety Network, and the INICC methods. In phase 2, we implemented the multidimensional approach for VAP. The INICC multidimensional approach included the following measures: (1) bundle of infection control interventions, (2) education, (3) outcome surveillance, (4) process surveillance, (5) feedback of VAP rates, and (6) performance feedback of infection control practices. We compared the rates of VAP obtained in each phase. A time series analysis was performed to assess the impact of our approach.

Results In phase 1, we recorded 2,376 mechanical ventilator (MV)-days, and in phase 2, after implementing the multidimensional approach, we recorded 28,181 MV-days. The rate of VAP was 31.14 per 1,000 MV-days during

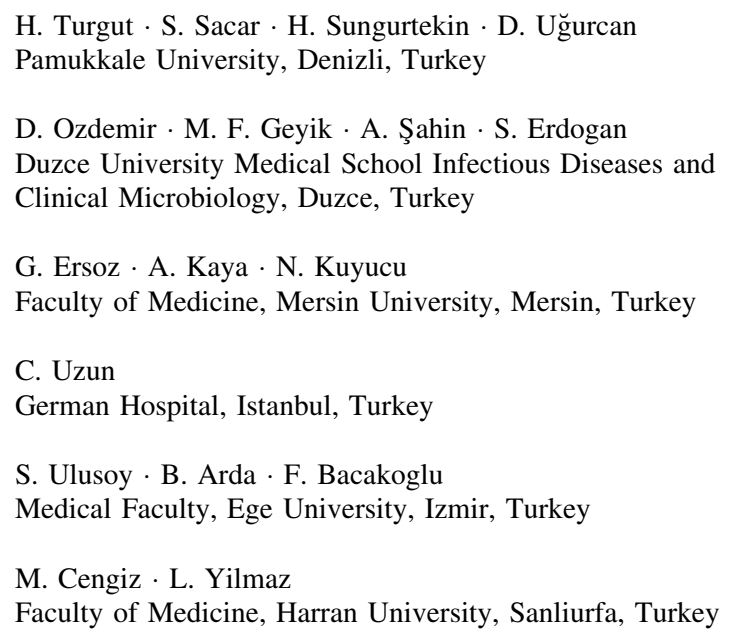


phase 1, and 16.82 per 1,000 MV-days during phase 2, amounting to a $46 \%$ VAP rate reduction ( $\mathrm{RR}, 0.54 ; 95 \%$ CI, 0.42-0.7; $P$ value, 0.0001.)

Conclusions The INICC multidimensional approach was associated with a significant reduction in the VAP rate in these adult ICUs of Turkey.

Keywords International Nosocomial Infection Control Consortium - Health care acquired infection .

Ventilator associated pneumonia - Developing countries . Adult intensive care unit · Multidimensional approach

\section{Introduction}

Ventilator-associated pneumonia (VAP) was reported as the primary cause of morbidity and mortality for deviceassociated infections (DAI) in the adult intensive care unit (AICU) setting, and has, therefore, been considered the most serious healthcare-associated infection (HAI) for critically ill patients $[1,2]$. Moreover, it has been widely shown that VAPs are one of the most common types of DAI, leading to substantial increases in ICU length of stay (LOS) and healthcare-related costs [1-3].

The burden of VAP has not been thoroughly analyzed in developing countries [1]. The importance of surveillance for measuring AICU patient infection risks, outcomes and processes in limited-resource countries is many times under-recognized, in spite of the fact that surveillance has long been reported a most effective tool for the reduction of VAP in the developed world [1, 4].

Since 2002, with the aim of contributing to address this public health problem also in developing countries, the International Nosocomial Infection Control Consortium (INICC) has been implementing an outcome and process surveillance program for ICUs in limited-resource settings [5].

The results of the INICC program showed that the rates of VAP differed considerably between ICUs from developing and developed countries. The rates in limitedresource ICUs were from 3 to 5 times higher [6-15].

The INICC multidimensional approach for VAP includes an infection prevention bundle which is based on practical and cost-effective infection control measures that are described in the guidelines published by the Society for Health Care Epidemiology of America (SHEA) and the Infectious Diseases Society of America (IDSA). These guidelines describe evidence-based recommendations and interventions for the prevention of VAP in the ICU setting [16].

To date, there are only a few studies that show successful interventions for the reduction of VAP, particularly in developing countries [1]. As a result, a systematic approach to address this burden in limited-resource settings is essential to serve as a guidance as to what strategies should be attempted for effectively tackling this problem [1].

In different studies conducted in INICC member hospitals from developing countries it has been demonstrated that outcome and process surveillance, within the scope of an intervention bundle that includes performance feedback of infection control practices, has successfully reduced DAIs [17-21].

The World Bank classifies economies into low income, middle income, or high income. As of 1 July 2011 lowincome economies are those that had average incomes of $\$ 1,005$ or less in 2010 ; lower-middle-income economies had average incomes of $\$ 1,006$ to $\$ 3,975$; upper-middleincome economies had average incomes of $\$ 3,976$ to $\$ 12,275$; and high-income had average incomes of $\$ 12,276$ or more. Low- and middle-income economies are commonly referred to as developing economies. However, this does not imply that economies in the same income group have reached similar stages of development or that highincome economies have reached a preferred or final stage of development. In this study we included hospitals of Turkey, which is an upper-middle-income economy.

In this study we determine the effects of the implementation of the INICC multidimensional approach for VAP reduction-which includes a bundle of infection control interventions, education, outcome and process surveillance, and feedback of VAP rates and of infection control practices - in the reduction of VAP in 11 AICUs of 10 INICC member hospitals in 10 cities of Turkey.

\section{Methods}

Setting and study design

This before-after, prospective cohort study was carried out in 11 AICUs of 10 INICC member hospitals, in 10 cities of Turkey. The participating hospitals have been actively involved in the INICC surveillance program for a minimum of 1 year, with an infection control team (ICT) comprising medical doctors with formal education and solid experience in infectious diseases, internal medicine, and/or hospital epidemiology, and infection control professionals (ICP).

The study period was 5 years and 4 months, from August 2003 to January 2009, and was divided into 2 phases: phase 1 (baseline period, consisting in the first 3 months of participation in the INICC program), and phase 2 (intervention period). The Institutional Review Board (IRB) at each hospital approved the study protocol.

Intervention period

The intervention period started after 3 months of participation in the INICC Surveillance Program. The average 
length of the intervention period was 28.64 months \pm SD 20.27 (range 6-72).The INICC multidimensional approach included the following practices: (1) bundle of infection control interventions, (2) education, (3) outcome surveillance, (4) process surveillance, (5) feedback of VAP rates, and (6) performance feedback of infection control practices.

\section{Bundle components}

Our bundle included the following interventions:

1. Active surveillance for VAP [16];

2. Adherence to hand-hygiene guidelines [16];

3. Maintenance of patients in a semi recumbent position $\left(30^{\circ}-45^{\circ}\right.$ elevation of the head of the bed) [22];

4. Performance of daily assessments of readiness to wean and use of weaning protocols [23];

5. Performance of regular oral care with an antiseptic solution [24];

6. Use of noninvasive ventilation whenever possible and minimization of the duration of ventilation [16];

7. Preferable use of orotracheal instead to nasotracheal intubation [16];

8. Maintenance of an endotracheal cuff pressure of at least $20 \mathrm{~cm} \mathrm{H}_{2} \mathrm{O}$ [16];

9. Removal of the condensate from ventilator circuits [16]; and keeping the ventilator circuit closed during condensate removal [16];

10. Change of the ventilator circuit only when visibly soiled or malfunctioning [16];

11. Avoidance of gastric overdistention [16];

12. Avoidance of histamine receptor $2(\mathrm{H} 2)$-blocking agents and proton pump inhibitors [16];

13. Use of sterile water to rinse reusable respiratory equipment [16].

We perform direct observation of $\mathrm{HH}$ compliance, duration of ventilation, and ventilation ratio use, using a structured observation tools at regularly scheduled intervals [5].

\section{Education}

Education of healthcare personnel involved training and sessions on the recommendations and interventions for the prevention of VAP in the ICU setting as described in the guidelines developed by the SHEA and IDSA [16].

INICC methodology

The INICC Surveillance Program includes two components: outcome surveillance (VAP rates and consequences) and process surveillance (adherence to hand hygiene and other basic preventive infection control practices) [5].
Investigators were required to perform outcome and process surveillance by filling in prospective data in specific forms at their ICUs. In turn, these forms were sent for their monthly analysis to the INICC office in Buenos Aires [5].

\section{Outcome surveillance}

The INICC Surveillance Program is focused on the methods and definitions for DAI developed by the US Centers for Disease Control and Prevention (CDC) for the National Nosocomial Infection Surveillance System (NNIS)/ National Health Safety Network (NHSN) program [25, 26]. However, the INICC methods have taken into consideration the different socioeconomic status and specific limitations of limited-resource countries, and were adapted for their application in this setting [5]. Outcome surveillance includes rates VAP per 1,000 device-days; microorganism profile, bacterial resistance, LOS, and mortality in their ICUs.

\section{Process surveillance}

Process surveillance is designed to monitor compliance with easily measurable, key infection control measures. It includes the surveillance of compliance rates for hand hygiene $(\mathrm{HH})$ practices and some specific infection control measures for VAP prevention.

$\mathrm{HH}$ compliance by healthcare workers (HCWs) is determined by measuring the frequency of $\mathrm{HH}$ performances when clearly indicated, and such practices are monitored by the hospital's ICP during randomly selected 1-h observation periods, three times a week. Although HCWs know that HH practices are regularly monitored, they are not actually aware of the precise moment in which observations are taking place [5].

ICPs were trained to detect $\mathrm{HH}$ compliance and record $\mathrm{HH}$ opportunities and compliance through direct observation. The INICC direct observation comprises the "Five Moments for Hand Hygiene," as recommended by the World Health Organization (WHO). The "Five Moments" were designed on the basis of the evidence concerning DAI prevention and control, and include the monitoring of the following moments: (1) before patient contact, (2) before an aseptic task, (3) after body fluid exposure risk, (4) after patient contact, and (5) after contact with patient surroundings [27].

Feedback of DA-HAI rates

Upon processing the hospitals' outcome surveillance data on a monthly basis, the INICC Research Team, at INICC Headquarters located in Buenos Aires, prepares and sends 
to each ICT a final report on the results of outcome surveillance rates; that is, monthly DA-HAI rates, LOS, bacterial profile and resistance, and mortality [5].

Feedback of DA-HAI rates is provided to HCWs working in the AICU by communicating the outcomes of the patients. The resulting rates are reviewed by the ICT at monthly meetings, where charts are analyzed, and statistical graphs and visuals are posted inside the ICU, to provide an overview of rates of DA-HAIs. This infection control tool is key to increase awareness about outcomes of patients at their ICU, enable the ICT and ICU staff to focus on the necessary issues and apply specific strategies for improvement of high DA-HAI rates.

\section{Performance feedback}

Upon processing the hospitals' process surveillance data on a monthly basis, the INICC Research Team, at INICC Headquarters located in Buenos Aires, prepares and sends to each ICT a final report on the results of process surveillance rates, including compliance with hand hygiene and preventive measures [5].

Performance feedback is provided to HCWs working in the AICU by communicating the assessment of practices routinely performed by them. The resulting rates are reviewed by the ICT at monthly meetings, where charts are analyzed, and statistical graphs and visuals are posted inside the ICU, to provide an overview of rates measuring compliance with infection control practices. This infection control tool is key to enable the ICT and ICU staff to focus on the necessary strategies for improvement of low compliance rates.

\section{Training and validation}

The INICC Chairman trained the principal and secondary investigators at hospitals on how to perform prospective surveillance according to the INICC methods [5]. Also, investigators were provided with training tools that described how to perform surveillance and complete surveillance forms. Investigators had continuous e-mail and telephone access to a support team at the INICC Central Office in Buenos Aires, Argentina, in charge of responding to all queries within $24 \mathrm{~h}$. The INICC Chairman further reviewed all queries and responses.

Surveillance forms for individual patients allow internal and external validation, because they include every clinical and microbiological criterion for each type of DAI, such as temperature, blood pressure, use of invasive devices, cultures taken, culture results, antibiotic use. Surveillance also includes a form where positive cultures are registered and matched with patients' forms.
On a monthly basis, participating hospitals submitted the completed surveillance forms to the INICC Central Office, where the validity of each case was checked and the recorded signs and symptoms of infection and the results of laboratory studies, radiographic studies, and cultures were scrutinized to assure that the NNIS System criteria for DAI were fulfilled.

The ICT member who reviewed the forms completed at the participating AICU was able to verify that criteria for infection had been met accurately in each case. Additionally, the original patient data forms were further validated at the INICC Central Office, before data on the reported infection were entered into the INICC's database. To that end, queries were submitted from INICC office in Buenos Aires to the ICT teams at each hospital, challenging those cases with suspected VAP, and data were uploaded after receiving the reply from hospital teams. Finally, the INICC team performed consistency analyses of database, such as age, gender, dates, among other data, and reviews of medical records that compared data registered in forms and data in medical records.

\section{Definitions}

We applied CDC NHSN definitions for VAP [26]. VAP is diagnosed in a mechanically ventilated patient with a chest radiograph that shows new or progressive infiltrates, consolidation, cavitation, or pleural effusion. The patient also must meet at least one of the following criteria: new onset of purulent sputum or change in character of sputum, organism cultured from blood, or isolation of an etiologic agent from a specimen obtained by tracheal aspirate, bronchial brushing or bronchoalveolar lavage, or biopsy [26].

\section{Statistical methods}

Patients' characteristics during baseline and during the last 3 months of the intervention period in each AICU were compared using Fisher's exact test for dichotomous variables and unmatched Student's $t$ test for continuous variables. Ninety-five percent confidence intervals (CI) were calculated using VCStat (Castiglia). Relative risk (RR) ratios with $95 \% \mathrm{CI}$ were calculated for comparisons of rates of VAP using EPI Info V6. $P$ values $<0.05$ by twosided tests were considered significant. Further, we explored the change in VAP rates following an ICU joining INICC by looking at the follow-up period stratified by 3 -month periods over the first year, 6-month periods over the second and third years of follow up and then yearly (to allow for fewer subjects in ICUs with longer periods of follow up). We calculated crude stratified rates, and using random effects Poisson regression to allow for clustering 
by ICU, we calculated IRR for each time period compared with the baseline 3 months. Device days were included in the model as an offset with the coefficient constrained to be zero (patients without MV during admission were excluded). We performed an additional regression considering "time since ICU started the intervention period" as a continuous variable (excluding the baseline period), and calculated the IRR for reduction in HAI for each 3-month period of follow up.

\section{Results}

During the study period, 4,312 patients, hospitalized for 55,268 days, in 11 AICUs were enrolled in the study, with a total of 30,557 mechanical ventilator (MV)-days. See Tables 1 and 2 .

Regarding patient characteristics, gender, patients with surgical stay, trauma, abdominal surgery, and with hepatic failure were similar in both periods. The age mean of patients was slightly lower during the intervention period. ASIS score, MV use ratio and MV duration means were higher during the intervention period. See Table 2.

Regarding process surveillance, $\mathrm{HH}$ compliance during intervention was improved by $14 \%$ (from 42 to $47.6 \%$ ); and nebulizer without turbidity was improved by $15 \%$ (from 45.2 to $52.15 \%$ ).

Position of the head in semi-recumbent position was high and similar during both periods. See Table 2.

During baseline, the VAP rate was 31.14 VAPs per 1,000 MV-days, and during intervention VAP rate was 16.82 per $1,000 \mathrm{MV}$ days (RR $0.54 ; 95 \%$ CI $0.42-0.7$; $P$ 0.0001). These results showed a $46 \% \mathrm{VAP}$ rate reduction. See Table 2.

We calculated the extra LOS and extra mortality of VAP in the overall period of the study. The average LOS of patients without infection was 8.2 days, and the mortality rate was $24.7 \%$. In patients with VAP, the LOS was

Table 1 Characteristics of participating adult intensive care units by type, country and hospital type

\begin{tabular}{lcc}
\hline Data & AICUs, $n(\%)$ & AICU patients, $n(\%)$ \\
\hline Type of AICU & & \\
Medical surgical & $10(91)$ & $3,051(71)$ \\
Medical & $1(9)$ & $1,261(29)$ \\
All AICUs & $11(100)$ & $4,312(100)$ \\
Type of hospital & & \\
Academic teaching & $10(91)$ & $4,259(99)$ \\
Private community & $1(9)$ & $53(1)$ \\
All hospitals & $11(100)$ & $4,312(100)$ \\
\hline
\end{tabular}

$A I C U$ adult intensive care unit
18.9 days (10.7 days of extra LOS) and the mortality was $32.3 \%$ (7.6\% extra mortality).

In comparison with baseline VAP rates for the 3 months before the intervention, VAP rates were $12 \%$ lower 9 months after the intervention. VAP rates were $33 \%$ lower in the second year, $25 \%$ in the third year, $30 \%$ in the fourth year and $56 \%$ in the fifth and sixth years (Table 3).

Microorganisms profile is shown in Table 4. Pseudomonas, Acinetobacter spp. and Staphylococcus aureus were the predominant agents during both periods.

Antibiotic resistance is shown in Table 5. The resistance rate of Acinetobacter spp. to imipenem, ciprofloxacin and piperacillin-tazobactam were high during baseline and intervention periods. There were no significant differences in resistance over the two periods.

\section{Discussion}

The burden of VAP in critically ill patients has been widely addressed in the literature worldwide. According to studies from developed [28] and developing countries [1, 3], the most serious clinical consequences attributable to VAP are increased mortality rates [3], significant morbidity [29], and increased LOS [3]. From an economic perspective, VAP is also responsible for significant increases in healthcare costs, as reported in both developed [28] and developing countries [3].

Most hospitals in limited-resource countries do not implement basic infection control programs, which results in a general unawareness of the incidence of VAP at their healthcare facilities [1]. In studies conducted in limitedresource countries, the rates of VAP have been determined to be from 3 to 5 times higher than in the developed countries [14, 30-32]. The baseline rate of VAP found in this study (31.14 per 1,000 MV-days) was more than tenfold higher than the US 1.8 VAP rate per 1,000 MV-days determined by the CDC/NSHN [33], and the 6.8 rate determined by KISS [34].

In comparison with VAP rates from other developing countries, our VAP baseline rate was similar to the first international INICC report published in 2006 (24.1 VAPs per 1,000 MV-days) [14], but higher than the second, third, and fourth international INICC report published in 2008 (19.5 VAPs per 1,000 MV-days) [30], 2010 (13.16 VAPs per 1,000 MV-days) [31], and 2012 (15.8 VAPs per 1,000 MV-days) [32]. Within the scope of other studies addressing the burden of VAPs in Turkey, the VAP rates found in previous studies from Turkey were also similar than the baseline VAP rate found in this study; in a multicentric study carried out in 12 hospitals in 2007, Leblebicioglu et al. [8] found a global VAP rate of 26.5 
Table 2 Patient characteristics, hand hygiene compliance, compliance with bundle to prevent ventilator-associated pneumonia, device use, and ventilator-associated pneumonia rates, in phase 1 (baseline period) and phase 2 (intervention period)

$V A P$ ventilator-associated pneumonia, $M V$ mechanical ventilator, $S D$ standard deviation, $A S I S$ average severity of illness score, $R R$ relative risk, $C I$ confidence interval

${ }^{\text {a }}$ Bed-days are the total number of days that patients are in the ICU during the selected time period

b MV-days: the total number of days of exposure to mechanical ventilation by all of the patients in the selected population during the selected time period

${ }^{c}$ MV use ratios were calculated by dividing the total number of MV-days by the total number of bed-days

\begin{tabular}{|c|c|c|c|c|c|}
\hline Patients' characteristics & Baseline & Intervention & $\mathrm{RR}^{\mathrm{a}}$ & $95 \% \mathrm{CI}$ & $P$ value \\
\hline $\begin{array}{l}\text { Study period by hospital in months, } \\
\text { mean } \pm \text { SD (range) }\end{array}$ & 3 & $\begin{array}{l}28.64 \pm 20.27 \\
\quad(6-72)\end{array}$ & - & - & - \\
\hline Number of patients, $n$ & 448 & 3,864 & - & - & - \\
\hline Bed-days, ${ }^{\mathrm{a}} n$ & 4,602 & 50,666 & & & \\
\hline No. of MV days, ${ }^{\text {b }} n$ & 2,376 & 2,8181 & & & \\
\hline MV duration, mean \pm SD & $5.3 \pm 10.1$ & $7.3 \pm 14.0$ & - & - & 0.003 \\
\hline MV use ratio ${ }^{c}$, mean & 0.52 & 0.56 & 1.08 & $1.03-1.12$ & 0.0005 \\
\hline Age in years, mean $\pm S D$ & $52.37 \pm 22.5$ & $49 \pm 21.6$ & - & - & 0.001 \\
\hline ASIS score, mean \pm SD & $3.34 \pm 1.0$ & $3.5 \pm 0.85$ & - & - & 0.004 \\
\hline Male, $n(\%)$ & $255(58)$ & $2,392(38)$ & 1.06 & $0.94-1.21$ & 0.343 \\
\hline Female, $n(\%)$ & $182(42)$ & $1,459(62)$ & - & - & - \\
\hline Surgical stay, $n(\%)$ & $51(11)$ & $353(9)$ & 0.82 & $0.61-1.1$ & 0.1723 \\
\hline Abdominal surgery, $n(\%)$ & $18(4)$ & $227(6)$ & 1.46 & $0.9-2.36$ & 0.12 \\
\hline Trauma, $n(\%)$ & $65(15)$ & $594(15)$ & 1.06 & $0.82-1.37$ & 0.658 \\
\hline Hepatic failure, $n(\%)$ & $7(2)$ & $28(1)$ & 0.46 & $0.2-1.06$ & 0.0624 \\
\hline Hand hygiene compliance, $\%(n / n)$ & $\begin{array}{l}41.94(656 / \\
1,564)\end{array}$ & $\begin{array}{l}47.61(8,257 / \\
17,344)\end{array}$ & 1.14 & $1.05-1.23$ & 0.002 \\
\hline $\begin{array}{l}\text { MV compliance semi-recumbent position } \\
\text { of the head }\left(30^{\circ}-45^{\circ}\right), \%(n / n)\end{array}$ & $\begin{array}{l}90.55(2,128 / \\
2,350)\end{array}$ & $\begin{array}{c}92(19,887 / \\
21,631)\end{array}$ & 1.02 & $0.97-1.06$ & 0.51 \\
\hline $\begin{array}{l}\text { MV compliance nebulizer without } \\
\text { turbidity, } \%(n / n)\end{array}$ & $\begin{array}{l}45.2(1,062 / \\
2,350)\end{array}$ & $\begin{array}{l}52.15(11,280 / \\
21,631)\end{array}$ & 1.15 & $1.08-1.23$ & 0.0001 \\
\hline VAP, $n$ & 74 & 474 & & & \\
\hline VAP rate per $1,000 \mathrm{MV}$ days ${ }^{\mathrm{b}}$ & 31.14 & 16.82 & 0.54 & $0.42-0.7$ & 0.0001 \\
\hline
\end{tabular}

Table 3 Ventilator-associated pneumonia rates stratified by length of participation of each intensive care unit in INICC

\begin{tabular}{lllrlll}
\hline Months since joining INICC & No. of ICUs & MV days & VAP & VAP rate/1,000 MV days & IRR accounting for clustering by ICU & $P$ value \\
\hline 1-3 months (baseline) & 11 & 2,376 & 74 & 31.14 & - & 1 \\
4-12 months & 11 & 6,639 & 176 & 26.51 & $0.88(0.665-1.16)$ & $0.67(0.473-0.95)$ \\
Second year & 8 & 5,672 & 89 & 15.7 & $0.75(0.5-1.13)$ & 0.361 \\
Third year & 4 & 5,818 & 89 & 15.3 & $0.7(0.45-1.06)$ & 0.167 \\
Fourth year & 3 & 7,617 & 99 & 13.0 & $0.44(0.232-0.835)$ & 0.094 \\
Fifth-sixth years & 2 & 2,435 & 21 & 8.62 & 0.012 \\
\hline
\end{tabular}

Poisson regression

INICC International Nosocomial Infection Control Consortium, ICUs intensive care units, VAP ventilator-associated pneumonia, $M V$ mechanical ventilator, $I R R$ incidence-rate ratio

VAPs per 1,000 MV-days. Similarly, in 2008, Erdem et al. [35] found a rate of 22.6 VAPs per 1,000 MV-days.

The considerable influence that a country's socioeconomic level and hospital type have over DAI in developing countries has been assessed in two studies. As regards hospital type, VAP rates in pediatric ICUs from academic hospitals were higher than those in private or public hospitals: 8.3 versus 3.5 VAPs per 1,000 MV-days [36]. In a study from neonatal ICU patients, the VAP rates in academic hospitals were significantly higher than in private or public hospitals: 13.2 versus 2.4 and 4.9 VAPs per 1,000 MV-days [37]. With regard to the country socioeconomic level, in a study conducted in pediatric ICUs it was shown that lower-middle-income countries had higher VAP rates than upper middle-income countries ( 9.0 vs. 0.5 per 1,000 MV-days) [36].

The positive impact of VAP reduction strategies proved effective a long time ago. In a previous study of INICC, we included this population of Turkey merged with the population of other 13 countries, but the reason why we have now reported these data from Turkey separately lies in the fact that this population has significantly different features and outcomes than the overall population of the previous study [38]. In the developed countries, it has been 
Table 4 Microorganism profile of ventilator-associated pneumonia in adult intensive care units divided into phase 1 and phase 2

\begin{tabular}{lll}
\hline Isolated microorganisms & Baseline & Intervention \\
\hline Pseudomonas spp., \% (n) & $32(22)$ & $30(119)$ \\
Acinetobacter spp., \% (n) & $22(12)$ & $33(130)$ \\
Staphylococcus aureus, \% (n) & $20(14)$ & $13(51)$ \\
Escherichia coli, \% ( $)$ & $9(6)$ & $5(20)$ \\
Klebsiella, \% $(n)$ & $7(5)$ & $11(42)$ \\
Serratia, \% $(n)$ & $3(2)$ & $1(5)$ \\
Candida, \% $(n)$ & $3(2)$ & $1(4)$ \\
Enterobacter spp., \% (n) & $1(1)$ & $2(7)$ \\
Proteus, \% (n) & $1(1)$ & $1(2)$ \\
Enterococcus & $1(1)$ & $0(0)$ \\
Streptococcus, \% $(n)$ & $0(0)$ & $1(5)$ \\
Stenotrophomonas spp., \% (n) & $0(0)$ & $1(4)$ \\
Coagulase-negative staphylococcus spp., \% & $0(0)$ & $1(3)$ \\
$(n)$ & & \\
Staphylococcus epidermidis, \% (n) & $0(0)$ & $1(2)$ \\
Total, \% (n) & $100(65)$ & $100(394)$ \\
\hline
\end{tabular}

Table 5 Antibiotic resistance of the most common ventilator-associated pneumonia related isolated microorganisms in adult intensive care units divided into phase 1 and phase 2

\begin{tabular}{llll}
\hline Isolated microorganisms & Baseline & Intervention & $P$ value \\
\hline Pseudomonas spp. & & & \\
$\quad$ Imipenem, resistance, \% & 43.3 & 40.6 & 0.7653 \\
Ceftazidime, resistance, \% & 64.5 & 46.5 & 0.0506 \\
Amikacin, resistance, \% & 23.5 & 13.8 & 0.4494 \\
$\quad$ Piperacillin, resistance, \% & 35.7 & 35.3 & 0.8019 \\
Acinetobacter spp. & & & \\
Imipenem, resistance, \% & 78.3 & 64.4 & 0.0609 \\
$\quad$ Ciprofloxacin, resistance, \% & 96.0 & 84.8 & 0.2143 \\
$\quad$ Piperacillin-Tazobactam, & 84.6 & 90.8 & 0.4953 \\
$\quad$ resistance, \% & & & \\
Staphylococcus aureus & & & 0.5050 \\
$\quad$ Methicillin resistance, \% & 80.0 & 73.2 & \\
\hline
\end{tabular}

demonstrated that the incidence of VAP can be substantially prevented and reduced by more than $30 \%$ through basic but effective measures, such as hand hygiene compliance, semi-recumbent positioning [39], early removal of endotracheal tubes [40], maintenance of endotracheal cuff pressure and continuous subglottic suctioning [41]. Similarly, it was shown in studies performed by INICC that implementation of a multi-dimensional approach for VAP - which includes a bundle of interventions, education, outcome and process surveillance, feedback of VAP rates, and performance feedback-resulted in significant reductions in rates of VAP in Argentina (51.28 vs. 35.50 VAPs per 1,000 MV-days) [17], China, amounting to a $79 \%$ cumulative VAP rate reduction during the 3-year study period [42], and in the pooled VAP rates of pediatric ICUs (31\% VAP rate reduction), [43] neonatal ICUs (33\% VAP rate reduction) [44] and adult ICUs (55.83\% VAP rate reduction) [38] of limited-resource countries.

The INICC multidimensional approach for VAP included the following elements. First, the implementation of an infection prevention bundle based on the guidelines published by the SHEA and the IDSA [16], which provide evidence-based recommendations and cost-effective infection control measures, which can be feasibly adapted to the ICU setting in developing countries. Second, education of HCWs about infection preventive measures. Third, VAP outcome surveillance by applying the definitions for DAI developed by the US CDC/NHSN $[25,26]$. Fourth, VAP process surveillance to monitor compliance with easily measurable infection control measures, including HH performance. Fifth, feedback of VAP rates. Sixth, performance feedback of process surveillance, particularly, by reviewing and discussing charts results at monthly infection control meetings.

During the study period, the high VAP rate at baseline was reduced from 31.14 to 16.82 per 1,000 MV days (RR $0.54 ; 95 \%$ CI $0.42-0.7 ; P$ 0.0001), showing a $46 \%$ VAP rate reduction. In comparison with baseline VAP rates for the 3 months before the intervention, VAP rates were $12 \%$ lower 9 months after the intervention. These VAP rates were further decreased by $33 \%$ in the second year, $25 \%$ in the third year, $30 \%$ in the fourth year and $56 \%$ in the fifth and sixth years.

In our study, some patients' characteristics, such as gender, patients with surgical stay, trauma, abdominal surgery, and with hepatic failure, showed similar patient intrinsic risk in both study periods. As regards the age mean of patients, it was slightly lower during the intervention period. By contrast, ASIS score, device use ratio and MV mean duration were higher during the intervention period, meaning that the patient intrinsic risk was higher in phase 2 .

After the implementation of the INICC multidimensional approach, we found an improvement in process surveillance rates, with $\mathrm{HH}$ compliance having being improved by $14 \%$ (from 42 to $47.6 \%$ ). Also, within our bundle elements, nebulizer without turbidity was improved by $15 \%$ (from 45.2 to $52.15 \%$ ), and position of the head in semi-recumbent position remained high and similar during the whole study period. According to the literature, $\mathrm{HH}$, lack of turbidity of nebulizer and semi-recumbent position of the head are some of the key elements to reduce the risk of VAP [45].

Regarding the microorganisms profile, we identified a predominance of Pseudomonas, Acinetobacter spp. and 
S. aureus during both periods. According to the scientific literature from Turkey, the predominant agents for VAP were Acinetobacter spp., methicillin-resistant $S$. aureus, and $P$. aeruginosa [35]. The resistance rate to antibiotics did not change during the study. The Acinetobacter spp. resistance to Imipenem, Ciprofloxacin and piperacillin-tazobactam was high during the baseline and intervention periods (Table 5). A recent study by Guner et al. [46] showed that treatment with tigecycline is sometimes used effectively to treat multi-drug resistant $A$. baumannii; since we do not have information regarding tigecycline use in our study, we are unable to compare these results with ours. Nevertheless, we consider this an important issue for future research.

\section{Study limitations}

Limitations of this study lie on the fact that our findings are not to be generalized to all AICU patients from Turkey; however, this study proved that a multidimensional approach is fundamental to understand and fight against the adverse effects of VAP in the AICU setting of Turkey. Second, the setting of 3-month baseline period may be short and might have overestimated the effect of the intervention; however, this duration of baseline period is common in the scientific literature. Finally, we could not quantify in detail information for each AICU on the compliance of each bundle component, and other non-quantifiable interventions included in our multidimensional approach, such as education and training.

\section{Conclusions}

This study is among the first scarce studies that have reported a substantial reduction in VAP rates in the AICU setting, proving this kind of infection control approach successful [1]. Despite higher patient intrinsic risk characteristics during phase 2, ICP at the INICC AICU setting were able to obtain successful prevention of VAP. Good as it is, it is worth highlighting that the reduction in VAP rates does not derive from surveillance itself. This systematically collected data should serve to guide healthcare professionals in their strategies for improvement of patient care practices, such as performance feedback [17, 18]. Therefore, it is essential to support educational efforts with regular feedback in the form of monthly incidence rates of VAPs to derive substantial benefit from preventive strategies [17, 18, 20, 47, 48].

We expect that these preventive strategies, proven effective in the INICC AICUs of Turkey by means of the implementation of the multidimensional approach for VAP prevention, results in a wider acceptance of infection control programs in hospitals worldwide, thus leading to significant VAP reductions. Through the INICC network, investigators are freely furnished with training and methodological tools to perform outcome and process surveillance, and to implement an effective infection prevention model for VAPs, and at the same time, the publication of these findings serves to foster relevant scientific evidencebased literature. For this reason, every hospital is invited to participate in the INICC project, which was set up to respond to the compelling need in the developing world to significantly prevent, control and reduce VAPs and their adverse effects.

Acknowledgments The authors thank the many health care professionals at each member hospital who assisted with the conduct of surveillance in their hospital, including the surveillance nurses, clinical microbiology laboratory personnel, and the physicians and nurses providing care for the patients during the study; without their cooperation and generous assistance this INICC would not be possible; Mariano Vilar, Débora López Burgardt, Santiago Suarez, Cecilia Cappelini, Denise Brito, Eugenia Manfredi, Luciana Soken, Dario Pizzuto, Yuan Ding, Katie Saunders, and Isaac Kelmeszes who work at INICC headquarters in Buenos Aires, for their hard work and commitment to achieve INICC goals; the INICC country coordinators (Altaf Ahmed, Carlos A. Álvarez Moreno, Anucha Apisarnthanarak, Luis E. Cuéllar, Bijie Hu, Hakan Leblebicioglu, Eduardo A. Medeiros, Yatin Mehta, Lul Raka, Namita Jaggi, and Toshihiro Mitsuda); the INICC Advisory Board (Carla J. Alvarado, Gary L. French, Nicholas Graves, William R. Jarvis, Patricia Lynch, Dennis Maki, Russell N. Olmsted, Didier Pittet, Wing Hong Seto, Syed Sattar, and William Rutala), who have so generously supported this unique international infection control network; and specially to Patricia Lynch, who inspired and supported us to follow our dreams despite obstacles. The funding for the activities carried out at INICC head quarters were provided by the corresponding author, Victor D. Rosenthal, and Foundation to Fight against Nosocomial Infections.

Conflict of interest All authors report no conflict of interest related to this article. Every hospital's institutional review board agreed to the study protocol, and patient confidentiality was protected by codifying the recorded information, making it only identifiable to the ICT. All authors submitted the ICMJE Form for Disclosure of Potential Conflict of Interest, and the conflict that the editors consider relevant to this article are disclosed here.

\section{References}

1. Arabi Y, Al-Shirawi N, Memish Z, Anzueto A. Ventilator-associated pneumonia in adults in developing countries: a systematic review. Int J Infect Dis. 2008;12:505-12. doi:10.1016/j.ijid.2008. 02.010 .

2. Rosenthal VD, Guzman S, Orellano PW. Nosocomial infections in medical-surgical intensive care units in Argentina: attributable mortality and length of stay. Am J Infect Control. 2003;31:291-5. (pii: S0196655302482016).

3. Rosenthal VD, Guzman S, Migone O, Safdar N. The attributable cost and length of hospital stay because of nosocomial pneumonia in intensive care units in 3 hospitals in Argentina: a prospective, matched analysis. Am J Infect Control. 2005;33:157-61. doi: 10.1016/j.ajic.2004.08.008. 
4. Rosenthal VD. Health-care-associated infections in developing countries. Lancet. 2011;377:186-8. doi:10.1016/S0140-6736(10) 62005-3.

5. Rosenthal VD, Maki DG, Graves N. The International Nosocomial Infection Control Consortium (INICC): goals and objectives, description of surveillance methods, and operational activities. Am J Infect Control. 2008;36:e1-12. doi:10.1016/j.ajic.2008.06.003.

6. Cuellar LE, Fernandez-Maldonado E, Rosenthal VD, CastanedaSabogal A, Rosales R, Mayorga-Espichan MJ, et al. Deviceassociated infection rates and mortality in intensive care units of Peruvian hospitals: findings of the International Nosocomial Infection Control Consortium. Rev Panam Salud Publica. 2008;24:16-24. (pii: S1020-49892008000700002).

7. Guanche-Garcell H, Requejo-Pino O, Rosenthal VD, MoralesPerez C, Delgado-Gonzalez O, Fernandez-Gonzalez D. Deviceassociated infection rates in adult intensive care units of Cuban university hospitals: international Nosocomial Infection Control Consortium (INICC) findings. Int J Infect Dis. 2011;15:e357-62. doi:10.1016/j.ijid.2011.02.001.

8. Leblebicioglu H, Rosenthal VD, Arikan OA, Ozgultekin A, Yalcin AN, Koksal I, et al. Device-associated hospital-acquired infection rates in Turkish intensive care units. Findings of the International Nosocomial Infection Control Consortium (INICC). J Hosp Infect. 2007;65:251-7. doi:10.1016/j.jhin.2006.10.012.

9. Mehta A, Rosenthal VD, Mehta Y, Chakravarthy M, Todi SK, Sen $\mathrm{N}$, et al. Device-associated nosocomial infection rates in intensive care units of seven Indian cities. Findings of the International Nosocomial Infection Control Consortium (INICC). J Hosp Infect. 2007;67:168-74.

10. Moreno CA, Rosenthal VD, Olarte N, Gomez WV, Sussmann O, Agudelo JG, et al. Device-associated infection rate and mortality in intensive care units of 9 Colombian hospitals: findings of the International Nosocomial Infection Control Consortium. Infect Control Hosp Epidemiol. 2006;27:349-56. doi:10.1086/503341.

11. Ramirez Barba EJ, Rosenthal VD, Higuera F, Oropeza MS, Hernandez HT, Lopez MS, et al. Device-associated nosocomial infection rates in intensive care units in four Mexican public hospitals. Am J Infect Control. 2006;34:244-7.

12. Rosenthal VD. Device-associated nosocomial infections in limited-resources countries: findings of the International Nosocomial Infection Control Consortium (INICC). Am J Infect Control. (2008);36:S171 e7-12. doi:10.1016/j.ajic.2008.10.009.

13. Cetinkaya Y, Yildirim G, Iskit AT, Özgultekin A, Turan G, Akgün $\mathrm{N}$ et al. (eds). Multi-center national prospective study to evaluate hand washing compliance in hospitals from Turkey. Behaviour comparison between different stratums. Proceedings and abstracts of the fifth pan-american congress of infection control and hospital epidemiology; 2004 October 7-10; Lima, Peru.

14. Rosenthal VD, Maki DG, Salomao R, Moreno CA, Mehta Y, Higuera F, et al. Device-associated nosocomial infections in 55 intensive care units of 8 developing countries. Ann Intern Med. 2006;145:582-91. (pii: 145/8/582).

15. Salomao R, Rosenthal VD, Grimberg G, Nouer S, Blecher S, Buchner-Ferreira $S$, et al. Device-associated infection rates in intensive care units of Brazilian hospitals: findings of the International Nosocomial Infection Control Consortium. Rev Panam Salud Publica. 2008;24:195-202. (pii: S1020-49892008000900006).

16. Coffin SE, Klompas M, Classen D, Arias KM, Podgorny K, Anderson DJ, et al. Strategies to prevent ventilator-associated pneumonia in acute care hospitals. Infect Control Hosp Epidemiol. 2008;29 Suppl 1:S31-40. doi:10.1086/591062.

17. Rosenthal VD, Guzman S, Crnich C. Impact of an infection control program on rates of ventilator-associated pneumonia in intensive care units in 2 Argentinean hospitals. Am J Infect Control. 2006;34:58-63.
18. Rosenthal VD, Maki DG, Rodrigues C, Alvarez-Moreno C, Leblebicioglu H, Sobreyra-Oropeza M, et al. Impact of International Nosocomial Infection Control Consortium (INICC) strategy on central line-associated bloodstream infection rates in the intensive care units of 15 developing countries. Infect Control Hosp Epidemiol. 2010;31:1264-72. doi:10.1086/657140.

19. Rosenthal VD, Guzman S, Pezzotto SM, Crnich CJ. Effect of an infection control program using education and performance feedback on rates of intravascular device-associated bloodstream infections in intensive care units in Argentina. Am J Infect Control. 2003:31:405-9. doi:10.1067/mic.2003.52.

20. Rosenthal VD, McCormick RD, Guzman S, Villamayor C, Orellano PW. Effect of education and performance feedback on handwashing: the benefit of administrative support in Argentinean hospitals. Am J Infect Control. 2003;31:85-92.

21. Rosenthal VD, Guzman S, Safdar N. Effect of education and performance feedback on rates of catheter-associated urinary tract infection in intensive care units in Argentina. Infect Control Hosp Epidemiol. 2004;25:47-50. doi:10.1086/502291.

22. Dellinger RP, Vincent JL. The surviving sepsis campaign sepsis change bundles and clinical practice. Crit Care. 2005;9:653-4. doi:10.1186/cc3952.

23. Burns KE, Adhikari NK, Meade MO. Noninvasive positive pressure ventilation as a weaning strategy for intubated adults with respiratory failure. Cochrane database of systematic reviews. 2003:CD004127. doi:10.1002/14651858.CD004127.

24. Tantipong H, Morkchareonpong C, Jaiyindee S, Thamlikitkul V. Randomized controlled trial and meta-analysis of oral decontamination with $2 \%$ chlorhexidine solution for the prevention of ventilator-associated pneumonia. Infect Control Hosp Epidemiol. 2008;29:131-6. doi:10.1086/526438.

25. Emori TG, Culver DH, Horan TC, Jarvis WR, White JW, Olson DR, et al. National nosocomial infections surveillance system (NNIS): description of surveillance methods. Am J Infect Control. 1991;19:19-35.

26. Horan TC, Andrus M, Dudeck MA. CDC/NHSN surveillance definition of health care-associated infection and criteria for specific types of infections in the acute care setting. Am J Infect Control. 2008;36:309-32. doi:10.1016/j.ajic.2008.03.002.

27. Sax H, Allegranzi B, Chraiti MN, Boyce J, Larson E, Pittet D. The World Health Organization hand hygiene observation method. Am J Infect Control. 2009;37:827-34. doi:10.1016/j.ajic.2009.07.003.

28. Safdar N, Dezfulian C, Collard HR, Saint S. Clinical and economic consequences of ventilator-associated pneumonia: a systematic review. Crit Care Med. 2005;33:2184-93. (pii: 00003246-200510000-00005).

29. Bouadma L, Wolff M, Lucet JC. Ventilator-associated pneumonia and its prevention. Curr Opin Infect Dis. 2012;25:395-404. doi:10.1097/QCO.0b013e328355a835.

30. Rosenthal VD, Maki DG, Mehta A, Alvarez-Moreno C, Leblebicioglu $\mathrm{H}$, Higuera $\mathrm{F}$, et al. International Nosocomial Infection Control Consortium report, data summary for 2002-2007, issued January 2008. Am J Infect Control. 2008;36: 627-37. doi:10.1016/j.ajic.2008.03.003.

31. Rosenthal VD, Maki DG, Jamulitrat S, Medeiros EA, Todi SK, Gomez DY et al. International Nosocomial Infection Control Consortium (INICC) report, data summary for 2003-2008, issued June 2009. Am J Infect Control. 2010;38:95-104 e2. doi:10.1016/ j.ajic.2009.12.004

32. Rosenthal VD, Bijie H, Maki DG, Mehta Y, Apisarnthanarak A, Medeiros EA, et al. International Nosocomial Infection Control Consortium (INICC) report, data summary of 36 countries, for 2004-2009. Am J Infect Control. 2012;40:396-407. doi:10.1016/ j.ajic.2011.05.020.

33. Dudeck MA, Horan TC, Peterson KD, Allen-Bridson K, Morrell G, Pollock DA, et al. National Healthcare Safety Network 
(NHSN) Report, data summary for 2010, device-associated module. Am J Infect Control. 2011;39:798-816. doi:10.1016/j.ajic.2011. 10.001 .

34. Geffers C, Gastmeier P. Nosocomial infections and multidrugresistant organisms in Germany: epidemiological data from KISS (the Hospital Infection Surveillance System). Dtsch Arztebl Int. 2011;108:87-93. doi:10.3238/arztebl.2011.0087.

35. Erdem I, Ozgultekin A, Inan AS, Dincer E, Turan G, Ceran N, et al. Incidence, etiology, and antibiotic resistance patterns of gram-negative microorganisms isolated from patients with ventilator-associated pneumonia in a medical-surgical intensive care unit of a teaching hospital in istanbul, Turkey (2004-2006). Jpn J Infect Dis. 2008;61:339-42.

36. Rosenthal VD, Jarvis WR, Jamulitrat S, Silva CP, Ramachandran B, Duenas L, et al. Socioeconomic impact on device-associated infections in pediatric intensive care units of 16 limited-resource countries: international Nosocomial Infection Control Consortium findings*. Pediatr Crit Care Med. 2012;13:399-406. doi: 10.1097/PCC.0b013e318238b260.

37. Rosenthal VD, Lynch P, Jarvis WR, Khader IA, Richtmann R, Jaballah NB, et al. Socioeconomic impact on device-associated infections in limited-resource neonatal intensive care units: findings of the INICC. Infection. 2011;39:439-50. doi:10.1007/ s15010-011-0136-2.

38. Rosenthal VD, Rodrigues C, Alvarez-Moreno C, Madani N, Mitrev Z, Ye G, et al. Effectiveness of a multidimensional approach for prevention of ventilator-associated pneumonia in adult intensive care units from 14 developing countries of four continents: findings of the International Nosocomial Infection Control Consortium*. Crit Care Med. 2012;40:3121-8. doi: 10.1097/CCM.0b013e3182657916.

39. Kollef MH. Ventilator-associated pneumonia. A multivariate analysis. JAMA. 1993;270:1965-70.

40. Kelleghan SI, Salemi C, Padilla S, McCord M, Mermilliod G, Canola $\mathrm{T}$, et al. An effective continuous quality improvement approach to the prevention of ventilator-associated pneumonia. Am J Infect Control. 1993;21:322-30.

41. Boyce JM, White RL, Spruill EY, Wall M. Cost-effective application of the centers for disease control guideline for prevention of nosocomial pneumonia. Am J Infect Control. 1985;13:228-32. (pii: 0196-6553(85)90063-X).

42. Tao L, Hu B, Rosenthal VD, Zhang Y, Gao X, He L. Impact of a multidimensional approach on ventilator-associated pneumonia rates in a hospital of Shanghai: findings of the International Nosocomial Infection Control Consortium. J Crit Care. 2012; doi:10.1016/j.jcrc.2011.12.018.

43. Rosenthal VD, Alvarez-Moreno C, Villamil-Gomez W, Singh S, Ramachandran B, Navoa-Ng JA, et al. Effectiveness of a multidimensional approach to reduce ventilator-associated pneumonia in pediatric intensive care units of 5 developing countries: international Nosocomial Infection Control Consortium findings. Am J Infect Control. 2011; doi:10.1016/j.ajic.2011.08.005.

44. Rosenthal VD, Rodriguez-Calderon ME, Rodriguez-Ferrer M, Singhal T, Pawar M, Sobreyra-Oropeza M, et al. Findings of the International Nosocomial Infection Control Consortium (INICC), Part II: impact of a multidimensional strategy to reduce ventilatorassociated pneumonia in neonatal intensive care units in 10 developing countries. Infect Control Hosp Epidemiol. 2012;33:704-10. doi: $10.1086 / 666342$.

45. Muscedere J, Dodek P, Keenan S, Fowler R, Cook D, Heyland D. Comprehensive evidence-based clinical practice guidelines for ventilator-associated pneumonia: prevention. J Crit Care. 2008;23:126-37. doi:10.1016/j.jcrc.2007.11.014.

46. Guner R, Hasanoglu I, Keske S, Kalem AK, Tasyaran MA. Outcomes in patients infected with carbapenem-resistant Acinetobacter baumannii and treated with tigecycline alone or in combination therapy. Infection. 2011;39:515-8. doi:10.1007/ s15010-011-0161-1.

47. Rosenthal VD, Guzman S, Safdar N. Reduction in nosocomial infection with improved hand hygiene in intensive care units of a tertiary care hospital in Argentina. Am J Infect Control. 2005;33:392-7. doi:10.1016/j.ajic.2004.08.009.

48. Higuera F, Rosenthal VD, Duarte P, Ruiz J, Franco G, Safdar N. The effect of process control on the incidence of central venous catheter-associated bloodstream infections and mortality in intensive care units in Mexico. Crit Care Med. 2005;33:2022-7. (pii: 00003246-200509000-00019). 